\title{
A Diabetes Education Multimedia Program in the Waiting Room Setting
}

Mohammad A. Khan · Sejal Shah · Aneta Grudzien · Nneamaka Onyejekwe · Pranab Banskota · Sarah Karim • Jing Jin · Yoonsang Kim · Ben S. Gerber

To view enhanced content go to www.diabetestherapy-open.com

Received: April 4, 2011 / Published online: August 22, 2011

(C) The Author(s) 2011. This article is published with open access at Springerlink.com

\section{ABSTRACT}

Introduction: This study evaluated the impact of a waiting room-administered, low-literacy, computer multimedia diabetes education program on patient self-management and provider intensification of therapy.

Mohammad A. Khan · Sejal Shah · Nneamaka Onyejekwe · Pranab Banskota · Sarah Karim Department of Internal Medicine/Primary Care, Care Improvement Collaborative - Strategies to Advance Rational Therapy Clinic, Stroger Cook County Hospital, Chicago, Illinois, USA

Aneta Grudzien · Ben S. Gerber

Department of Medicine, University of Illinois at Chicago, Chicago, Illinois, USA

Jing Jin · Yoonsang Kim

Division of Epidemiology and Biostatistics, University of Illinois at Chicago, Chicago, Illinois, USA

Ben S. Gerber $(\square)$

Institute for Health Research and Policy (M/C 275), University of Illinois at Chicago, 1747 West Roosevelt Road, Chicago, IL 60608. Email: bgerber@uic.edu

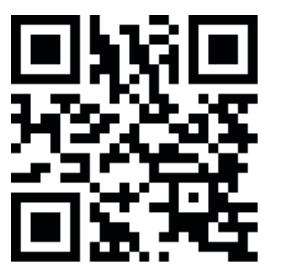

Enhanced content for this article is available on the journal web site: www.diabetestherapy-open.com
Methods: In this randomized, controlled trial, 129 participants either viewed a computer multimedia education program (intervention group) or read an educational brochure (control group) while in the waiting room. Participants were uninsured, primarily ethnic minority adults with type 2 diabetes receiving care from a county clinic in Chicago, Illinois. Wilcoxon test, t-test, and linear mixed model analyses evaluated changes in diabetes knowledge, selfefficacy, behaviors, medications prescribed, hemoglobin A1c $\left(\mathrm{HbA}_{1 \mathrm{c}}\right)$, and blood pressure levels over 3 months. Results: During the study period, there was an increase in the number of oral diabetes medications prescribed over three months to multimedia users compared with those in the control group $(P=0.017)$. $\mathrm{HbA}_{1 \mathrm{c}}$ declined by 1.5 in the multimedia group versus 0.8 in the control group $(P=0.06)$. There were no differences between groups in changes in blood pressure levels, self-efficacy, and most diabetes-related behaviors. Self-reported exercise increased in the control group compared with the multimedia group (0.9 days/week vs. 0.1 days/week, $P=0.016)$. Conclusion: Multimedia users received a greater intensification of diabetes therapy, but demonstrated no difference in selfmanagement in comparison with those receiving 
educational brochures. The availability of a computer multimedia program in the waiting room appears to be a novel and acceptable approach in providing diabetes education for underserved populations.

Keywords: computer-assisted instruction; diabetes education; ethnic groups; health literacy

\section{INTRODUCTION}

There is a growing interest in investigating computer-based diabetes education in the ambulatory environment, largely due to limited funding and clinical staff. ${ }^{1}$ Successful officebased computerized education programs may help to ease the burden of busy providers with insufficient time available for education and counseling. ${ }^{2,3}$ This technology-based solution may be even more valuable as populations with diabetes become older and sicker and have more complex issues. ${ }^{4}$

Computer multimedia programs may provide additional advantages over alternative educational methods, such as text-based materials. By including audiovisual elements (video, icons, and simple graphics), computer multimedia may assist patients with low health literacy. ${ }^{5}$ Video storytelling, a form of persuasive communication, may be an effective tool in health promotion. ${ }^{6}$ Furthermore, computer interactivity allows for the tailoring of information to individual needs, interests, and competencies, and the assessment of knowledge for reinforcement purposes.

By incorporating computer multimedia programs into waiting-room areas, patients have easy access to educational materials. Patients who receive physician counseling at the same time as educational materials may be more likely to change negative behaviors. ${ }^{7}$ Conversely, patient attention to educational messages prior to provider encounters may influence patient-provider decision making and diabetes management. The benefits of multimedia education in diabetes self-care may be derived from both improved patient self-management as well as greater intensification of therapy.

Between 2000 and 2003, we conducted a multicenter, randomized, controlled trial that evaluated the impact of an office-based, low-literacy, multimedia diabetes education program on an underserved population with type 2 diabetes. ${ }^{8}$ A study of 255 individuals with diabetes showed that waiting room use of the multimedia program improved perceived susceptibility to complications, with the greatest impact observed among users with lower health literacy. In a subgroup analysis of those with both low health literacy and poor glycemic control (hemoglobin A1c $\left[\mathrm{HbA}_{1 \mathrm{c}}\right] \geq 9$ ), there was a significantly greater improvement in $\mathrm{HbA}_{1 \mathrm{c}}$ by multimedia users. However, program adoption by staff and integration into clinical work flow remained challenging throughout this implementation process. ${ }^{8}$

Following study completion, the program was successfully implemented in an urban diabetes self-management clinic, Care Improvement Collaborative - Strategies to Advance Rational Therapy (CIC-START). This "safety-net" county clinic serves uninsured patients with diabetes who do not have a primary care physician. Patients received an individualized risk assessment, goal setting, group education, and lifestyle counseling supplemented with computer multimedia education. In addition, patients met with providers to intensify medication therapy and meet goals of glycemic and blood pressure control. Within 6 months, these patients were transitioned to a communitybased provider within the county health system for long-term chronic disease care. 
As the computer multimedia program was heavily used in the office setting, with a high level of adoption by clinical staff and integration into clinical work flow, it provided a unique opportunity for study. We consequently evaluated the impact of supplementary computer-based diabetes education on patient self-management and intensification of therapy. We hypothesized that multimedia users would have greater improvement in self-management behaviors, therapy intensification, and glycemic control over a 3-month period.

\section{METHODS}

\section{Living Well with Diabetes Multimedia Program}

The Living Well with Diabetes multimedia program has been described in detail elsewhere. ${ }^{8}$ We developed 19 bilingual computer multimedia lessons on diabetes self-management targeting Hispanic and African American populations. To create the program, the research team video recorded over 160 testimonials from African American and Hispanic patients with diabetes related to diabetes self-care, emphasizing barriers to care, challenges, and personalized solutions they or family members had encountered. For example, a woman with advanced diabetic retinopathy related a story promoting the need for regular dilated eye examinations: 'It's normal to have concerns... to be anxious about what might be some bad news... but at least you can affect that news, if you hurry up and get involved right away... if you don't put it off.'

Program content includes an introduction to diabetes, blood glucose management, oral medications and insulin, nutrition and physical activity, depression and stress, oral hygiene, and the prevention of complications (including eye, foot, cardiovascular, and kidney diseases). Each lesson targets a specific self-care objective according to Gagné's theory of learning and the component display theory. ${ }^{9,10}$ Lessons include video stories, graphic animations, professional narration, interactive quizzes, and feedback. While the lesson plans for the English and Spanish versions are very similar through translation, different testimonials from various subjects were used to relate both language- and culturally-appropriate information to the users. Multimedia navigation was provided through a simplified interface, including forward/ backward buttons for user control.

\section{Participants and Data Collection}

The study was performed between February 2007 and June 2008 and was approved by the Stroger Cook County Hospital Institutional Review Board. Medical assistants referred potential participants to research assistants located in the CIC-START clinic. These patients were new to CIC-START and typically did not have primary-care providers, and presented as walk-ins without appointments. Some were referred by the ambulatory screening center or emergency room. Eligibility criteria included age $\geq 18$ years, verbal fluency in English, and responsibility for their own diabetes selfmanagement. Of 146 patients approached with study information, 129 enrolled (88\%). Those who declined enrollment indicated the following reasons: not being the person responsible for their own care, imminent relocation, lack of interest, or lack of financial incentive. Research assistants obtained written informed consent from participants who were eligible and expressed interest. Random allocation took place by the research assistant pulling a card out of a box, with each card indicating group assignment (computer multimedia program vs. control).

The computer multimedia program was available for patient use in waiting areas prior 
to attending other educational activities and provider encounters, as this allowed for productive learning rather than experiencing the usual prolonged stress in anticipation of interacting with the provider. Those who were randomized to view the Living Well with Diabetes multimedia program spent an average of 30 minutes on five lessons, depending on interests and needs. The research assistant ensured that the computer was functional, reviewed the touch-screen controls with participants, and remained in the room to make sure that participants were actively engaged with the program. Computer log data confirmed participant interactions and ensured fidelity in intervention delivery. Individuals receiving the control experience were taken to a separate area and given an American Diabetes Association brochure on self-management ("Living with Diabetes," written at under a 6th-grade reading level). Each participant was given sufficient time to read through the information. In addition, a short diabetes crossword puzzle based on the brochure was distributed.

Following computer use or a read-through of the brochure, all participants received traditional diabetes self-management education. This included group educational sessions, individualized risk assessment and goal setting procedures, and lifestyle training (with a focus on healthy eating and physical activity). All participants were given passports to record goals, targets of therapy, action plans, vital signs, and $\mathrm{HbA}_{1 \mathrm{c}}$ levels. Participants were seen monthly in the clinic by physicians trained in internal medicine. These physicians were not informed of the participants' group assignments. Study participants underwent measurements upon enrollment prior to educational experiences and again after 3 months' duration. Those who missed their scheduled appointment were called at home to reschedule.

\section{Assessments}

$\mathrm{HbA}_{1 \mathrm{c}}$ was obtained via phlebotomy following National Glycohemoglobin Standardization Program (NGSP) standards. Weight and height measures were performed, with participants removing heavy clothing and shoes. Blood pressure readings were conducted by clinical staff following a standard protocol. The research assistants asked participants about the number of blood pressure and diabetes medications taken prior to clinical encounters. Medications were routinely verified by clinic physicians.

Healthy literacy levels were assessed at baseline using the Rapid Estimate of Adult Literacy in Medicine - Short Form (REALM-SF). ${ }^{11}$ This measure is a 7-item word recognition test that has been validated with excellent agreement with the 66-item REALM instrument by grade levels.

The following measures were performed at baseline and repeated at 3 months by research assistant interviews. The Spoken Knowledge in Low Literacy in Diabetes Scale (SKILL-D) diabetes knowledge test required responses to 10 open-ended questions (eg, 'What are the signs and symptoms of high blood sugar?'), scored as percentage correct. ${ }^{12}$ Self-care behaviors related to diabetes self-management were evaluated through the Summary of Diabetes Self-Care Activities Measure (SDSCA). ${ }^{13}$ This tool measures 11 core items relating to diet, exercise, blood sugar testing, foot care, medication adherence, and smoking. Additional questions to assess adherence came from a 4-item measure developed by Morisky et al. in 1986: forgetting to take medicine; carelessness about taking medicine; not taking medicine when feeling better; and not taking medicine when feeling worse after taking medicine. ${ }^{14}$ Self-efficacy was assessed via a previously validated 12 -item instrument that correlated with $\mathrm{HbA}_{1 \mathrm{c}}$; each item included a Likert-type scale from $1-4 .{ }^{15}$ 


\section{Statistical Analysis}

Analyses were conducted using SAS v 9.2 statistical software, with significance defined as $P<0.05$ using intent-to-treat principles. To compare baseline participant characteristics, t-tests or Wilcoxon rank sum tests were used to evaluate for differences in continuous variables, such as age, between two intervention groups, and Chi-square tests were used to evaluate for differences in discrete variables, such as ethnicity. T-tests or Wilcoxon rank sum tests were used to compare changes over time in survey outcomes between the intervention and control groups. An evaluation of differences in the number of diabetes medications was performed with and without adjustment for baseline insulin use.

A linear mixed effects model was used to account for heterogeneity among the patients (SAS PROC MIXED). Change in $\mathrm{HbA}_{1 \mathrm{c}}$ over time was treated as random, since the change over time differs from patient to patient. We observed large variability in baseline $\mathrm{HbA}_{1 \mathrm{c}}$ measures across participants, especially among those whose $\mathrm{HbA}_{1 \mathrm{c}}$ was $>7 \%$. Therefore, we treated the intercepts as random for those whose $\mathrm{HbA}_{1 \mathrm{c}} \geq 7 \%$ at the first visit. The model equation was (for participant $i$ and visit $j$ ):

$$
\begin{aligned}
\mathrm{HbA}_{1 c i j}= & \beta_{0}+\beta_{1} \text { Group }_{i}+\beta_{2 i} \text { Time }_{j}+\beta_{3} \\
& \text { Group x Time }_{i j} \\
+ & \beta_{4 i} \mathrm{I}_{i}+\beta_{\mathrm{s}} \mathrm{I} \times \text { Time }_{i j}+\varepsilon_{i j}
\end{aligned}
$$

where Group=1 for the computer-based education group and 0 for the literature-based education group; Time $=1$ for the second visit and 0 for the first visit; and $I$ is an indicator that a participant's $\mathrm{HbA}_{1 \mathrm{c}}$ is $\geq 7 \%$ at the first visit.

\section{RESULTS}

Of the 129 participants who completed the consent form and baseline assessment, 67 were randomized to the multimedia intervention
Figure 1. Study flow diagram.

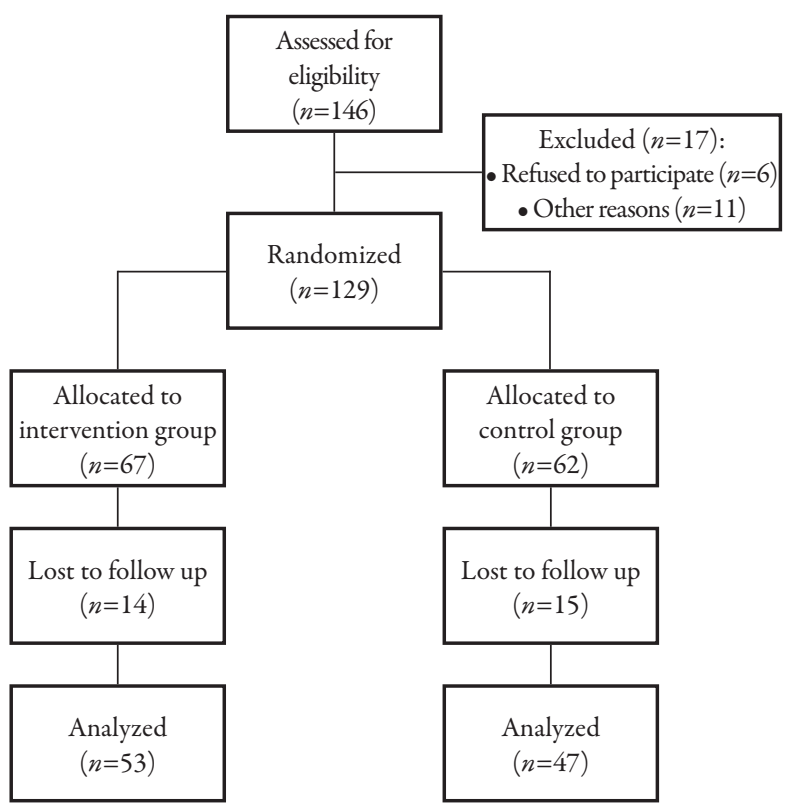

group and 62 to the brochure control group (Figure 1). At 3 months, 53 participants in the intervention group (79\%) and 47 in the control group (76\%) completed follow-up data collection and were analyzed $(P=0.65)$. There were no significant differences between those who completed the study and those who did not, based on gender $(P=0.88)$, ethnic background $(P=0.34)$, age $(P=0.91)$, number of diabetes medications $(P=0.36), \mathrm{HbA}_{1 \mathrm{c}}(P=0.49)$, health literacy $(P=0.66)$, or body mass index $(\mathrm{BMI})$ $(P=0.42)$. Reasons for dropping out of the study included relocation $(n=2)$, phone disconnection $(n=9)$, and leaving the county health system $(n=6) ; 12$ participants were lost to follow up.

Overall, the participants had a mean age of 51.5 years (standard deviation $[\mathrm{SD}] \pm 11.7$ ) and a mean BMI of $32.6 \mathrm{~kg} / \mathrm{m}^{2}( \pm 7.8)$. Fifty-seven percent were male and $92 \%$ were of minority ethnicity (Hispanic, African American, or Asian), and the average health literacy was at the 5thor 6th-grade level. There were no significant differences between the intervention and control groups at baseline (Table 1). 
Table 1. Baseline demographic and physical characteristics.

\begin{tabular}{lccc}
\hline Demographic & $\begin{array}{c}\text { Intervention group } \\
(n=67)\end{array}$ & $\begin{array}{c}\text { Control group } \\
(\boldsymbol{n}=62)\end{array}$ & $\boldsymbol{P}$-value \\
\hline Age, mean $(\mathrm{SD})$ & $52.4(11.4)$ & $50.5(12.0)$ & 0.35 \\
BMI $\left(\mathrm{kg} / \mathrm{m}^{2}\right)(\mathrm{SD})$ & $32.4(6.6)$ & $32.8(9.1)$ & 0.80 \\
Ethnicity, $n(\%)$ & & & 0.57 \\
Hispanic & $17(25)$ & $17(29)$ & \\
African American & $37(55)$ & $26(44)$ & \\
White & $1(1)$ & $3(5)$ & \\
Asian & $10(15)$ & $12(20)$ & \\
Other & $2(3)$ & $1(2)$ & \\
Gender, $n(\%)$ & & & \\
Male & $38(57)$ & $36(58)$ & 0.45 \\
Female & $29(43)$ & $26(42)$ & \\
Health literacy, mean $(\mathrm{SD})$ & $5.6(1.7)$ & $5.8(1.4)$ & \\
\hline
\end{tabular}

$\mathrm{SD}=$ standard deviation.

\section{Self-Management}

The mean diabetes knowledge score on the SKILL-D increased in both groups (0.6 for the intervention and 0.7 for the control group) (Table 2). There were no significant between-group differences with respect to diabetes knowledge change $(P=0.59)$. The participants' perceived self-efficacy also increased throughout the study (1.2 for those in the intervention group and 2.6 for the control group); however, the difference between groups in the degree of increased selfefficacy was not statistically significant $(P=0.20)$. There were no between-group differences in change in score related to self-reported diet $(P=0.27)$, foot care $(P=0.50)$, or medication adherence according to the Morisky scale $(P=0.63)$. The average amount of exercise days were virtually the same between the groups at baseline, but after 3 months the control group participants reported an average of one more day of exercise $(P=0.016)$.

\section{Intensification of Therapy}

During the course of the study, both groups revealed an increase in the number of diabetes medications they were taking (Table 2). When compared to the control group, the multimedia intervention group had an increased number of diabetes medications prescribed after 3 months $(P=0.017)$. This remained significant after adjustment for baseline insulin use. However, there were no between-group differences in insulin use $(P=0.81)$ or antihypertensive medications prescribed $(P=0.71)$ during the 3 month intervention study period .

\section{$\mathrm{HbA}_{1 \mathrm{c}}$ and Blood Pressure Outcomes}

After 3 months, $\mathrm{HbA}_{1 \mathrm{c}}$ was reduced by 1.5 among intervention-group participants and 0.8 among control-group participants (test for differential 
change, $P=0.06$ based on the linear mixed model). There were no significant betweengroup differences for change in systolic blood pressure $(P=0.94)$ or diastolic blood pressure $(P=0.46)$ (Table 2).

\section{DISCUSSION}

This study demonstrated a greater intensification of diabetes medication therapy among users of a computer multimedia diabetes educational

Table 2. Self-management and intensification of therapy outcomes.*

\begin{tabular}{|c|c|c|c|c|c|c|}
\hline & \multicolumn{2}{|c|}{$\begin{array}{l}\text { Intervention group } \\
\qquad(n=53)\end{array}$} & \multicolumn{2}{|c|}{$\begin{array}{l}\text { Control group } \\
\quad(n=47)\end{array}$} & \multirow{2}{*}{$\begin{array}{l}P \text {-value } \\
\text { (group at } \\
\text { baseline) }\end{array}$} & \multirow{2}{*}{$\begin{array}{c}P \text {-value } \\
\text { (group } \mathrm{x} \\
\text { time) }\end{array}$} \\
\hline & Baseline & 3 months & Baseline & 3 months & & \\
\hline Diabetes knowledge (SKILL-D), mean (SD) & $6.5(1.9)$ & $7.1(2.3)$ & $6.8(2.1)$ & $7.5(2.0)$ & 0.45 & 0.59 \\
\hline Diabetes self-efficacy, mean (SD) & $36.0(8.0)$ & $37.2(7.0)$ & $35.8(6.0)$ & $38.4(7.8)$ & 0.89 & 0.20 \\
\hline Medication adherence (Morisky), mean (SD) & $1.0(1.2)$ & $0.8(1.1)$ & $1.2(1.2)$ & $0.8(1.0)$ & 0.45 & 0.63 \\
\hline Exercise (SDSCA), mean (SD) & $3.3(2.5)$ & $3.4(2.2)$ & $3.4(2.5)$ & $4.3(2.2)$ & 0.93 & 0.016 \\
\hline Home glucose monitoring (SDSCA), mean (SD) & $2.9(3.0)$ & $4.1(2.9)$ & $2.8(2.8)$ & $5.1(2.5)$ & 0.76 & 0.30 \\
\hline Diabetes diet (SDSCA), mean (SD) & $2.9(2.7)$ & $3.4(2.3)$ & $3.7(2.5)$ & $3.9(2.6)$ & 0.16 & 0.27 \\
\hline Medication adherence (SDSCA), mean (SD) & $5.0(2.7)$ & $5.0(2.9)$ & $5.6(2.3)$ & $6.2(1.8)$ & 0.28 & 0.29 \\
\hline Diabetes foot care (SDSCA), mean (SD) & $4.9(1.2)$ & $5.3(1.2)$ & $4.7(1.3)$ & $5.4(1.3)$ & 0.50 & 0.50 \\
\hline $\mathrm{HbA}_{1 \mathrm{c}}(\%)$, mean $(\mathrm{SD})$ & $9.1(2.5)$ & $7.6(1.8)$ & $9.4(2.7)$ & $8.6(2.5)$ & 0.53 & 0.060 \\
\hline Systolic BP (mmHg), mean (SD) & $139(26.0)$ & $136(24.5)$ & $138(19.9)$ & $136(18.2)$ & 0.98 & 0.94 \\
\hline Diastolic BP (mmHg), mean (SD) & $80(12.9)$ & $79(11.3)$ & $79(9.6)$ & $80(11.8)$ & 0.89 & 0.46 \\
\hline Number of blood pressure medications, $n$ (\%) & & & & & 0.45 & 0.71 \\
\hline 0 & $24(45)$ & $10(19)$ & $25(53)$ & $17(36)$ & & \\
\hline 1 & $17(32)$ & $19(36)$ & $14(30)$ & $15(32)$ & & \\
\hline 2 & $7(13)$ & $12(23)$ & $7(15)$ & $10(21)$ & & \\
\hline 3 & $5(9)$ & $6(11)$ & $1(2)$ & $5(11)$ & & \\
\hline 4 & $0(0)$ & $6(11)$ & $0(0)$ & $0(0)$ & & \\
\hline Number of oral diabetes medications, $n(\%)$ & & & & & 0.84 & 0.017 \\
\hline 0 & $20(38)$ & $2(4)$ & $17(36)$ & $12(26)$ & & \\
\hline 1 & $21(30)$ & $26(49)$ & $17(36)$ & $22(47)$ & & \\
\hline 2 & $12(23)$ & $25(47)$ & $13(28)$ & $13(28)$ & & \\
\hline Insulin use, $n(\%)$ & $10(19)$ & $11(21)$ & $16(34)$ & $19(40)$ & 0.08 & 0.81 \\
\hline
\end{tabular}

$\mathrm{BP}=$ blood pressure; $\mathrm{HbA}_{\mathrm{lc}}=$ hemoglobin $\mathrm{Alc} ; \mathrm{SD}=$ standard deviation; $\mathrm{SDSCA}=$ Summary of Diabetes Self-Case Activities Measure; SKILL-D=Spoken Knowledge in Low Literacy in Diabetes Scale.

*Note: there is missing survey data for diabetes knowledge $(n=10)$, self-efficacy $(n=13)$, medication adherence (Morisky, $n=20)$, and SDSCA $(n=11)$. 
program compared with those receiving an educational brochure. In addition, there was an accompanying trend towards improvement in glycemic control, though the study was not powered to detect differences in this outcome. These findings suggest that multimedia education prior to provider encounters, in conjunction with other diabetes education efforts, may help in reaching therapeutic goals.

Previous evidence supports an increase in perceived complications among users of the Living Well with Diabetes program. ${ }^{8}$ When the program is provided immediately prior to clinical encounters, it may motivate patients, raise awareness of therapy goals, and potentially increase engagement and influence decisionmaking with providers. One additional advantage of multimedia use in this setting is that it eases the workload of busy providers. The potential benefits achieved from multimedia program use may not require substantial provider or staff time, though in this study the time spent on various educational tasks was not formally studied. In general, the CIC-START clinic was able to employ systematic change with multimedia adoption, serving as an example for how computer-based methods can be implemented for ambulatory diabetes education.

Similar to a prior study with the same multimedia program, we did not see evidence for improvement in self-reported diabetes-related behaviors in multimedia users. ${ }^{8}$ We believe that the program may not further alter selfmanagement behaviors beyond other traditional methods, including group meetings, goal setting, and lifestyle training. Also, additional knowledge is often insufficient for behavioral change and improved health. At the same time, informal experience suggests that prior multimedia use increases engagement by patients in additional educational programs. Potentially, the greatest value for educational multimedia may occur before an initial encounter, to encourage patients to learn more about diabetes and help them feel more comfortable in an educational environment.

With respect to self-reported physical activity, there was an improvement in physical activity among participants receiving brochures compared with multimedia users. We are highly skeptical that the brochure had a significant impact upon activity levels; instead, we suspect that multimedia users observing videos of exercises may be more critical of their own exercise efforts and rate their activity levels lower. Alternatively, this finding may be due to chance alone.

This study did demonstrate a positive change in the number of oral diabetes medications taken where a majority of participants were above their goal in $\mathrm{HbA}_{1 \mathrm{c}}$. Other studies that looked at "clinical inertia" (lack of intensification when needed during clinical encounters) frequently focused on provider feedback and system-level interventions, like automated reminders. ${ }^{16,17}$ Strategies typically address common provider barriers, such as providers overestimating the care provided, having various reasons to avoid intensification, and lacking education and training on getting patients to reach therapy goals. ${ }^{18}$ In our study, providers may have been more aggressive in therapy intensification, with a specific focus on glycemia management. Indeed, more powerful educational methods might influence patients and make them more receptive to treatment, thus indirectly reducing clinical inertia. ${ }^{19}$

Other studies have demonstrated the clinical benefits of computer-based diabetes education. Multimedia education programs designed for those with low health literacy have been shown to increase diabetes knowledge independent of health literacy level. ${ }^{20}$ One systematic review found that 16 of 19 trials showed a significant improvement in at least one outcome with 
computerized diabetes education. ${ }^{21}$ A second review of 25 studies that assessed interactive computer-based programs (for a wide range of conditions) also found improved outcomes. ${ }^{1}$ Seven of these studies showed equivalent or more effective education when comparing computer programs with staff educators. However, computer-based educational programs vary widely in features, scope, implementation, and use, so it remains difficult to generalize their impact. Furthermore, there remains a lack of evidence from rigorous study on economic impact and clinical outcomes.

In general, it is difficult to evaluate newer technologies for their effectiveness in the clinical environment when there is a lack of adoption (eg, poor integration into the workflow patterns). In this study, multimedia education had been adopted by clinical staff for several years, and study results reflect more realistic conditions that are more likely to be sustainable. Important aspects of successful computerbased education implementation include: (1) detailed planning with attention to current clinical procedures; (2) evaluation of impact on office workflow patterns; (3) consideration of alterations in staff involvement, time, and responsibilities; (4) evaluation of privacy; and (5) cost and maintenance. Further research on implementation and translation will help expand computer-based education methods to other environments. For example, nurse case managers and community health workers may offer computer multimedia programs as part of ongoing diabetes self-management support in other settings.

There are a number of strengths to this study. We incorporated a randomized, controlled study design to evaluate multimedia learning in a unique clinical setting that has successfully adopted this form of education. Through clinical workflow integration, there is a high level of reach for multimedia education. This translates into a novel approach to studying a vulnerable population consisting of low-income, primarily ethnic minority, uninsured adults with type 2 diabetes in a resource-limited environment. However, there were limitations to this trial. This study included participants from a single clinical location, and may not be applicable to other settings. Further implementation research is necessary to examine the issues involved with translating this approach using multimedia education. We evaluated short-term outcomes, which may not reflect the long-term impact of improved educational efforts, especially after patients have been transitioned to other providers in the community. Some outcomes, including $\mathrm{HbA}_{1 \mathrm{c}}$, may not have been adequately powered to detect significant differences at the 5\% significance level. Finally, the clinic implemented a multimodal approach to diabetes education, including multiple avenues of educational opportunities. While both intervention and control groups experienced comparable educational opportunities, it may be difficult to ascertain the benefits of specific components and their interactions with computer-based learning.

\section{CONCLUSION}

In summary, we evaluated a novel approach to enhancing diabetes education using a low literacy computer multimedia program in the waiting room setting. Participants using this program were more likely to have an intensification of oral diabetes therapy with a trend towards improved glycemic control. Informally, the program was found to be acceptable to both patients and staff. Additional study of implementation across other ambulatory settings will help better determine the ultimate value of multimedia in diabetes education. 


\section{ACKNOWLEDGMENTS}

The Agency for Healthcare Research and Quality provided funding for the development of the Living Well with Diabetes multimedia software (U18 HS11092). None of the authors declare any conflict of interest. We thank Mr. Alex Sokolovsky of the Department of Medicine at the University of Illinois at Chicago for his help in the preparation of this manuscript. Ben Gerber is the guarantor for this article, and takes responsibility for the integrity of the work as a whole.

Open Access. This article is distributed under the terms of the Creative Commons Attribution Noncommercial License which permits any noncommercial use, distribution, and reproduction in any medium, provided the original author(s) and source are credited.

\section{REFERENCES}

1. Fox MP. A systematic review of the literature reporting on studies that examined the impact of interactive, computer-based patient education programs. Patient Educ Couns. 2009;77:6-13.

2. Wofford JL, Smith ED, Miller DP. The multimedia computer for office-based patient education: a systematic review. Patient Educ Couns. 2005;59:148-157.

3. Mechanic D, McAlpine DD, Rosenthal M. Are patients' office visits with physicians getting shorter? N Engl J Med. 2001;344:198-204.

4. Chen LM, Farwell WR, Jha AK. Primary care visit duration and quality: does good care take longer? Arch Intern Med. 2009;169:1866-1872.

5. Schwartzberg JG, VanGeest JB, Wang CC, eds. Understanding Health Literacy: Implications for Medicine and Public Health. Chicago: American Medical Association; 2005.

6. Hinyard LJ, Kreuter MW. Using narrative communication as a tool for health behavior change: a conceptual, theoretical, and empirical overview. Health Educ Behav. 2007;34:777-792.
7. Kreuter MW, Chheda SG, Bull FC. How does physician advice influence patient behavior? Evidence for a priming effect. Arch Fam Med. 2000;9:426-433.

8. Gerber BS, Brodsky IG, Lawless KA, et al. Implementation and evaluation of a lowliteracy diabetes education computer multimedia application. Diabetes Care. 2005;28:1574-1580.

9. Gagne's theory of instruction. In: Driscoll M. Psychology of Learning for Instruction. Boston: Allyn \& Bacon; 1994:329-358.

10. Merrill D. Component display theory. In: Reigeluth CM, ed. Instructional Design Theories and Models. Volume 1: An Overview of Their Current Status. Hillsdale, NJ: Lawrence Erlbaum Associates; 1983:279-333.

11. Arozullah AM, Yarnold PR, Bennett CL, et al. Development and validation of a short-form, rapid estimate of adult literacy in medicine. Med Care. 2007;45:1026-1033.

12. Rothman RL, Malone R, Bryant B, et al. The spoken knowledge in low literacy in diabetes scale: a diabetes knowledge scale for vulnerable patients. Diabetes Educ. 2005;31:215-224.

13. Toobert DJ, Hampson SE, Glasgow RE. The summary of diabetes self-care activities measure: results from 7 studies and a revised scale. Diabetes Care. 2000;23:943-950.

14. Morisky DE, Green LW, Levine DM. Concurrent and predictive validity of a self-reported measure of medication adherence. Med Care. 1986;24:67-74.

15. Gerber BS, Pagcatipunan M, Smith EV Jr, et al. The assessment of diabetes knowledge and self-efficacy in a diverse population using Rasch measurement. J Appl Meas. 2006;7:55-73.

16. Ziemer DC, Miller CD, Rhee MK, et al. Clinical inertia contributes to poor diabetes control in a primary care setting. Diabetes Educ. 2005;31:564-571.

17. Ziemer DC, Doyle JP, Barnes CS, et al. An intervention to overcome clinical inertia and improve diabetes mellitus control in a primary care setting: Improving Primary Care of African Americans with Diabetes (IPCAAD) 8. Arch Intern Med. 2006;166:507-513.

18. Phillips LS, Branch WT Jr, Cook CB, et al. Clinical inertia. Ann Intern Med. 2001;135:825-834.

19. Reinharth D. Clinical inertia. Ann Intern Med. 2002;137:547-548. 
20. Kandula NR, Nsiah-Kumi PA, Makoul G, et al. The relationship between health literacy and knowledge improvement after a multimedia type 2 diabetes education program. Patient Educ Couns. 2009;75:321-327.
21. Austin Boren S, Gunlock TL, Krishna S, Kramer TC. Computer-aided diabetes education: a synthesis of randomized controlled trials. AMIA Annu Symp Proc. 2006:51-55. 